\title{
MÉTODOS DIAGNÓSTICOS PARA OS PATÓGENOS ALIMENTARES: CAMPYLOBACTER SP., SALMONELLA SP. E LISTERIA MONOCYTOGENES
}

\author{
R.B. de Andrade, T. Gemelli, L.P. Dall Onder, K. Cristina, T. de Brito, A.A.L. Barboza, B.G. de Brito
}

Instituto de Pesquisa Veterinária “Desidério Finamor", Estrada do Conde, 6.000, CEP 92990-000, Eldorado do Sul, RS, Brasil. E-mail: andbink@gmail.com

\section{RESUMO}

\begin{abstract}
Os métodos moleculares de detecção rápida e eficaz de lotes de aves infectados por bactérias como Salmonella sp. Campylobacter sp. e Listeria monocytogenes são importantes para reduzir a frequência da transmissão destes patógenos entre os lotes de aves e aos consumidores de produtos de origem animal. Recentemente, as técnicas de biologia molecular, em especial a reação em cadeia polimerase, que permite a amplificação específica de segmentos de DNA, têm possibilitado novos rumos na identificação de bactérias supracitadas, reduzindo o tempo de cultivo e ampliando a confiabilidade das provas diagnósticas. A utilização da biologia molecular por laboratórios de diagnóstico humano e animal, assim como em programas de controle de qualidade de alimentos e produtos de origem animal, já é realidade e tende a se expandir rapidamente. O objetivo deste artigo é fazer uma breve revisão dos testes diagnósticos convencionais e moleculares para identificar Campylobacter sp., Salmonella sp. e Listeria monocytogenes. Concluindo, o diagnóstico molecular é um campo em avanço científico e tecnológico, no qual novas técnicas moleculares estão em desenvolvimento para o diagnóstico de bactérias em alimentos.
\end{abstract}

PALAVRAS-CHAVE: Diagnóstico, aves, Salmonella sp., Campylobacter sp., Listeria monocytogenes.

\section{ABSTRACT}

DIAGNOSTICMETHODSFORTHEFOODPATHOGENSCAMPYLOBACTERSP., SALMONELLA SP. AND LISTERIA MONOCYTOGENES. The molecular methods for quick and efficient detection of chicken lots infected by bacteria such as Salmonella sp. Campylobacter sp. and Listeria monoytogenes is basic for the effort to reduce the frequency of the transmission between chicken lots and to the consumers of poultry products. Recently, the development of techniques involving molecular biology, especially polymerase chain reaction, which allows the specific enlargement of segments of DNA, has been making new procedures possible for the identification of the abovementioned bacteria, reducing the time necessary for the tests and enhancing the reliability of the resulting diagnoses. The use of molecular biology in laboratories for human and animal diagnosis, as well as in quality control programs for foods and products of animal origin is already a reality and has tended to expand quickly. The objective of this article is to present a brief review of the conventional diagnostic and molecular tests for the identification of Campylobacter sp., Salmonella sp. and Listeria monocytogenes. In conclusion, molecular diagnosis is a field undergoing scientific and technological advancement, in which new molecular techniques are under development for the diagnosis of bacteria in foods.

KEY WORDS: Diagnosis, chicken, Salmonella sp., Campylobacter sp., Listeria monocytogenes.

\section{INTRODUÇÃO}

As infecções alimentares representam ainda hoje um sério problema de sanidade pública pela sua frequência elevada, mortalidade e pelo grande número de micro-organismos que podem estar envolvidos em um simples evento epidêmico. Diversos patógenos alimentares são conhecidos por causarem doenças, estando veiculados a alimentos e água, e entre esses sabe-se que as bactérias constituem um grande grupo de micro-organismos causadores de doenças. A transmissão de muitos patógenos aos seres humanos ocorre pela má conservação dos alimentos, manipulação inadequada e consumo de alimentos crus entre outros. Salmonella sp. e Campylobacter sp. são os agentes de maior implicação em infecções alimentares e se unem a Listeria monocytogenes pela importância das eventuais sequelas (FORTUNA; FRANCO, 2005). Orisco microbiológico do consumo de aves e produtos derivados crus inclui contaminação por esses três patógenos alimentares. 
O gênero Salmonella geralmente causa ataques que envolvem um grande número de pessoas. A Salmonella sp. é uma das principais causas de doença de origem alimentar tendo alta frequência em todo mundo, estando associada a prejuízos econômicos, dificuldades comerciais e queda na produção (BARROS, 2002). Na década de 1990, surtos de toxinfecção alimentar foram relatados no Estado do Rio Grande do Sul e, dentre os casos, cerca de um terço foram identificados como provocados por alimentos contaminados com Salmonella sp. (KONEMAN et al., 2001).

As campilobacterioses, por outro lado, ocorrem como casos esporádicos, porém o Campylobacter sp. é uma bactéria que pode ser transmitida pelo contato direto com animais ou com carcaças de aves contaminadas, pela ingestão de alimentos ou água, por meio de fezes de pessoas com infecção ativa ou por transmissão a grupos de risco. As fontes principais incluem produtos lácteos não pasteurizados, consumo de carnes e produtos de aves mal cozidas, alimentos não cozido que podem sofrer contaminação cruzada com produtos e carnes de aves (YAN et al., 2005). A listeriose causada pela L. monocytogenes apresenta distribuição mundial, aparecendo com mais frequência em climas temperados e também nos tropicais (JEYASEKARAN et al., 1996). Pode ocorrer em todas as espécies de animais domésticos, sendo mais comum em ruminantes, coelhos e aves (CORRÊA, 1992). Os indivíduos em condições suscetíveis demonstram altas taxas de contaminação por L. monocytogenes. Essa bactéria principalmente intracelular é um patógeno emergente que vem sendo relacionado a diversos surtos de doenças de origem alimentar principalmente por estar presente no trato gastrointestinal dos animais, sendo muito comum a contaminação da carcaça e cortes de carne na etapa de abate ou no processamento incorreto (DeDIol et al., 2002). A contaminação pode ocorrer em cada etapa da produção de alimentos, iniciando na verificação da matéria-prima, transformação, conservação e consumo final dos alimentos. A ingestão desses patógenos ou das suas toxinas contidas nos alimentos é a causa das infecções gastrointestinais.

Os testes bioquímicos podem apresentar alguma variabilidade em razão da ação de fatores ambientais sobre a expressão gênica; baixo poder discriminatório em micro-organismos com pouca variabilidade genética e o risco de interpretações errôneas, quando se utiliza um número limitado de testes (GANDRA et al., 2008). A necessidade de vários dias a semanas até os resultados serem obtidos torna-se um problema importante (ROONEY et al., 2004). A busca da metodologia ideal para o diagnóstico das salmoneloses, campilobacterioses e listerioses nos animais, nos alimentos e no homem começou no momento da descrição do micro-organismo, sendo desenvolvidas diversas alternativas de métodos diagnósticos como: imunoensaios, imunodifusão, aglutinação em látex e hibridização do DNA (BLACKBURN, 1993).

Atualmente há necessidade de técnicas de detecção de infecções que demandem menor tempo de resposta e maior precisão de diagnóstico, principalmente para monitorização da produção animal, fabricação de alimentos e produto final (SANTOS et al., 2001). Portanto, técnicas de amplificação de ácidos nucleicos in vitro têm sido usadas como auxílio e podem tornar-se substitutas do processo de diagnóstico convencional (Oliveira et al., 2002). As ferramentas da biologia molecular permitem uma identificação precisa, rápida e com custos reduzidos. Entre essas ferramentas, destacam-se a reação em cadeia da polimerase (PCR), a ribotipagem, clonagem e análise de restrição (BARON et al., 1994).

A técnica de PCR vem sendo utilizada para a deteç̧ão de diversos micro-orgamismos, destacando-se Listeria monocytogenes, Campylobacter sp. e Salmonella. (SANTOSet al., 2001). Oobjetivo desteartigoéfazer uma breve revisão dos testes diagnósticos convencionais e moleculares para identificar essas três bactérias, como descrito a seguir.

\section{Salmonella sp.}

\section{Diagnóstico convencional}

A Salmonella sp.é mais facilmente isolada de uma amostra de fezes. Entretanto, nas chamadas febres entéricas, uma cultura do sangue é o procedimento mais indicado para revelar o micro-organismo durante as duas primeiras semanas (KonEMAN et al., 2001). A microbiologia convencional utiliza para o diagnóstico: isolamento, identificação bioquímica e caracterização antigênica. Para a identificação final da presença de Salmonella sp. as fases de préenriquecimento, enriquecimento seletivo, isolamento em meio sólido, seleção de colônias suspeitas e sorologia são necessárias.

Já no isolamento em meio sólido, alguns ágares, dentre os vários disponibilizados pelos laboratórios, são indicados pelo Ministério da Agricultura, Pecuária e Abastecimento, o ágar Hektoen, ágar Rambach, MacConkey, verde brilhante suplementado com novabiocina, e o XLT4 (chamado de ágar xilose lisina tergitol 4). Além de seletivos, esse ágares são meios diferenciais, porque as colônias das bactérias se multiplicam com diferentes características.

Nas etapas de deteçãa, os testes bioquímicos utilizados apresentam características que nos permitem observar a mudança de $\mathrm{pH}$ e alteração de coloração dos meios de cultura, quando houver crescimento bacteriano. O meio SIM (Sulphur Indol Motility) determina se os micro-organismos têm motilidade ou não, sendo positivo para a Salmonella sp. Na presença de Salmonella sp. o meio TSI (Triple Sugar Iron) apresenta bisel alcalino com produção 
de gás positiva ou negativa e o meio LIA (Lysine Iron Agar) mostra-se alcalino na base e com ou sem presença de gás $\mathrm{H}_{2} \mathrm{~S}$. O caldo ureia apresenta reação de urease-negativa para a presença de Salmonella sp. A interpretação dos resultados dos testes é realizada após a incubação a $37^{\circ} \mathrm{C}$ por 24 horas. As colônias que apresentarem a leitura dos testes bioquímicos preliminares compatíveis com Salmonella sp. passam pela caracterização bioquímica definitiva com testes parautilizaçãodocitratoemalonato, desidrolação da arginina, transformação da fenilalanina, descarboxilação da lisina e ornitina, fermentação de carboidratos, prova de Voges-Proskauer e prova do vermelho de metila. Para confirmação do perfil esperado para Salmonella sp., prossegue-se a caracterização antigênica com soro antissomático O polivalente de Salmonella $\mathrm{sp}$, a identificação final de sorovar, é realizada pelos laboratórios credenciados ou de referência (BRASIL, 1995). No isolamento de salmonelas oriundas de amostras clínicas alguns fatores podem interferir como: administração de antimicrobianos que podem retardar o seu crescimento, como a competição com outros micro-organismos, e a sua eliminação de maneira intermitente em baixo número (STONE et al., 1994a).

Essa metodologia tradicional ou microbiologia convencional para detecção de Salmonella sp. requer no mínimo quatro dias para obtenção de resultado negativo. As indústrias de alimentos necessitam de resultadosem menor tempo para reduzir a estocagem de produtos e custos associados, assim, métodos rápidos para detecção de Salmonella sp., por exemplo, o ensaio imunoenzimático - ELISA são utilizados com frequência por causa do seu benefício de detecção rápida e eficiente (FLowers et al., 1988).

Na realização do ELISA, têm sido utilizados anticorpos policlonais e monoclonais, que detectam grande parte dos sorovares de Salmonella sp., sendo quealguns destes ensaios são disponibilizados comercialmente em forma dekits prontos para ouso. Os kits possuem diferentes especificidades e sensibilidades na detecção de Salmonella sp., por causa da ocorrência de resultados falsos negativos (resultados que se apresentam positivos na meto-dologia tradicional) e resultados falsos positivos (no qual apresentam negativos na metodologia tradicional) influenciados por fatores referentes aos componentes do kit, às amostras e micro-organismos pesquisados (BEUMER et al., 1991). Portanto, o teste de ELISA aparece como uma alternativa diagnóstica, entretanto, devido à ocorrência de resultados quenão estão de acordocom a microbiologia convencional, esse teste diagnóstico permanece incerto na detecção de Salmonella sp.

\section{Diagnóstico molecular}

Entre os métodos utilizados para a identificação de Salmonella sp. destacam-se a caracterização bioquímica, sorotipagens, suscetibilidade a antimicrobianos e sorologia que, embora apresentem alta confiabilidade, requerem um longo tempo para a identificação do micro-organismo (RALl et al., 2005). A análise por PCR diminui o tempo deidentificação e detecção da salmonelose, de dias para poucas horas, auxiliando as análises de rotina de laboratórios clínicos e industriais, facilitando também a detecção de organismos não adaptados ao cultivo convencional (RAHN 1992; COHEN, 1993).

Por ser uma técnica altamente específica, a PCR pode ser realizada utilizando o DNA cromossomal ou mesmo o DNA plasmidial, sendo assim possível traçar o perfil genético de um organismo a partir de genes conhecidos e únicos para a espécie (DoubLET et al., 2008).

Devido ao fato da PCR detectar uma região única nmum a maioria das cepas, codificar para proteínas com importância na patogenicidade da bactéria enão apresentar homologia com outros micro-organismos (STONE et al.,1994b). Entre os iniciadores utilizados para detecção de salmonelas encontram-se inv $A$, IS200, hin, H-li, iagAB, spvR, viaB, mkfA, ompC, oriC, tendo estes iniciadores a especificidade como a principal diferença. Como exemplo é possível citar que o gene inv $A$ estaria presente nas espécies $S$. enteria e $S$. bongori, enquanto o gene iag $A B$ identificaria apenas o sorovares S. enterica subespécie I(BAuMLERetal.,1997).

HOORfar et al. (1999) relataram que a PCR não é vulnerável a reações atípicas e não depende de variações fenotípicas evitando, assim, resultados falso-negativos fornecidos pela técnica microbiológica. Segundo Gálan et al. (1992), o invA é um gene de Salmonella sp. que codifica uma proteína de invasão celular, sendo muito conservado dentro do gênero Salmonella e, portanto, muito utilizado nos laboratórios. SANTOS et al. (2001) avaliaram a especificidade, seletividade e sensibilidade dos oligonucleotídeos iniciadores (primers) 159 (5'GTGAAATTATCGCCACGTTCGGGCAA3') e 141 (5'TCATCGCACACGTCAAAGGACC3') derivados do gene invA na detecção de nove culturas-padrão de Salmonella, obtendo uma amplificação de DNA com aproximadamente $284 \mathrm{pb}$ em todas as amostras analisadas. Resultados semelhantes foram obtidos por RAHN et al. (1992) ao realizarem ensaios de especificidade e seletividade com iniciadores derivados deste gene em 630 amostras de salmonelas, de 21 gêneros. A associação dos iniciadores derivados dos genes invA e invB elimina a possibilidade da ocorrência de falsos-negativos, elevando assim a especificidade da PCR (STONE et al., 1994b).

Tuchilli et al. (1995), utilizando tecidos de pintos infectados com Salmonella sp., demonstraram que a sensibilidade da PCR foi maior do que no isolamento bacteriano em amostras com infecções na fase inicial, intermediária e tardia, demonstrando-se ainda muito 
eficaz para infecções latentes. Hudson et al. (2000) analisaram a virulência das salmonelas de aves silvestres e atribuíram a presença do gene de invasão invA em todas as amostras pesquisadas. A utilização da PCR na detecção de salmonela em carnes, fezes, tecidos, sangue e leite é uma estratégia muito utilizada, SCHRANK (2000) ressalta a alta sensibilidade e especificidade desta técnica para a identificação de Salmonella em produtos agrícolas.

O gene-alvo $\operatorname{omp} C$ é citado para a detecção de Salmonella sp., e os genes-alvo SdfI, ViaB e Spy na identificação de Salmonella enterica enterica sorotipo Enteridis, Typhi e Typhimurium, respectivamente (Kumar et al., 2006; Alvarez et al., 2004).

Um dos fatores limitantes para a detecção de agentes microbianos através da PCR em amostras de alimentos, clínicas e ambientais, é a presença de substâncias as quais inibem ou reduzem a eficiência da amplificação como sais biliares nas fezes, o grupo heme no sangue, substâncias húmicas no solo, proteinases no leite e ureia na urina; por este motivo diferentes técnicas são empregadas para diminuir a inibição da PCR e/ou para separar as bactérias dos inibidores da PCR (AL-SOUd; RADSTRÖM, 1998). Alguns fatores que podem inibir a eficiência da PCR podem ser reduzidos através da extração do DNA de Salmonella sp. que utilizam fenol-clorofórmio principalmente durante a extração de DNA total, apresentando assim resultados satisfatórios na análise de amostras com vários interferentes (SAMBROOK; RUSSELL, 2006).

\section{Campylobacter sp.}

\section{Diagnóstico convencional}

O isolamento do agente é o procedimento mais indicado para diagnosticar a campilobacteriose, no entanto, o Campylobacter sp. é encontrado normalmente em baixas concentrações nos espécimes analisados, exceto em carcaças de aves recentemente processadas (CARVALHO et al., 2002). No diagnóstico de Campylobacter jejuni e Campylobacter coli são utilizadas fezes, conteúdo cecal e da cloaca, jejuno e também fígado. $\mathrm{O}$ meio de cultura mais utilizado é o ágar base campilobacter incubado por 36 a 48 horas à $42^{\circ} \mathrm{C}$, em microaerobiose e na identificação do agente encontra-se bastonete delgado e curvo, Gram negativo, colônia translúcida de gotas d'água, lisa, convexa, brilhante e o crescimento pode ser confluente.

O isolamento é confirmado com aglutinação em látex e os testes bioquímicos para C. jejuni são: oxidase positiva, urease negativo, TSI negativo (fermentação e produção de gás sulfídrico ausente) e hidrólise do hipurato de sódio positivo (Revolledo, 2009). Para manutenção das amostras, a utilização de ambientes livres de oxigênio $\left(100 \% \mathrm{~N}_{2}\right)$, adicionados de $0,01 \%$ de bissulfito de sódio sob refrigeração, pode aumentar em até 100 vezes o tempo de estoque viável do agente, quando comparado com o armazenamento a $25^{\circ} \mathrm{C}$, mantido as mesmas condições (AMERICAN..., 2001). Não se recomenda o uso de velas para gerar ambiente microaerófilo; dá-se preferência à extração do gás atmosférico com uso de bomba a vácuo e posterior introdução de uma combinação de gases, armazenados em cilindros (CHRISTOPHER et al., 1982). A técnica de plaqueamento direto é mais eficiente para quantificar Campylobacter sp. em carcaças de aves do que o método de número mais provável - NMP (Revolledo; Ferreira, 2009). Nas pesquisas qualitativas em superfícies de equipamento e utensílios envolvendo um grande número de amostras, dá-se preferência à técnica do suabe. Com o auxílio de um bastão embebido em meio de cultura, faz-se esfregaço sobre a superfície da amostra, retornando-o para o caldo ou dispensando o material nele contido diretamente em ágares seletivos (AMERICAN..., 2001).

$\mathrm{O}$ isolamento de $C$. jejuni de alguns alimentos e de água pode ser facilitado utilizando uma fase de pré-enriquecimento com incubação por 4 horas a $37^{\circ}$ $\mathrm{C}$ em meio não-seletivo antes da incubação a $42^{\circ} \mathrm{C}$ (BARNES et al., 1997). Em meios com alta umidade, as colônias tendem à coalescência, dificultando a contagem, embora essa seja uma característica importante apresentada pelo gênero nos cultivos em meios sólidos. Para a obtenção de meios mais secos, pode-se deixar as placas por uma noite em temperatura ambiente, em ausência de luz, ou introduzir papel filtro adicionado de glicerol no ambiente de incubação das placas (Hunt et al., 2001). No primeiro isolamento, observam-se colônias translúcidas, acinzentadas, tendendo à coalescência, podendo ser rasas, opacas e marrom-acizentadas com discreta margem delimitada (AMERICAN..., 2001). A morfologia ea motilidade devem ser observadas em microscopia de campo escuro ou de contraste de fase. C. jejuni em cultivo apresenta-se curvo, em forma de "s" ou em bastonete espiralado; variam entre 0,2 e $1 \mathrm{mcm}$ de diâmetro e entre 0,5 e $5 \mathrm{mcm}$ de comprimento, com movimentos em saca-rolha. Deve-se sempre observar que em culturas velhas podem apresentar formas cocoides e não-móveis.

Utiliza-se para colorações a fucsina de ZiehlNeelsen, que obteve resultados melhores do que com a safranina (Hunt et al., 2001). No isolamento, transfere-se uma colônia para o HIA-RB (heart infusion agar plates supplemented with $5 \%$ defibrinated rabbitblood), incubado a $42^{\circ} \mathrm{C}$, em microaerofilia, por 24 horas. Rotineiramente, são utilizados os testes de catalase, redução de nitrato, utilização da glicose, produção de gás sulfídrico, tolerância à glicina e ao cloreto de sódio, capacidade de multiplicação nas temperaturas de $25^{\circ} \mathrm{C}$ e $42^{\circ} \mathrm{C}$, resistência a antimicrobianos, prova do TMAO (Trimethylamine n-oxide) 
ehidrólise do hipurato. Por meio de hemaglutinação passiva, identificaram 60 sorotipos de C. jejuni, e constataram que este e $C$. coli apresentam antígenos diferentes com baixa correspondência entre si (BOHRER et al., 1987).

\section{Diagnóstico molecular}

A rapidez na identificação do agente etiológico através da detecção do seu material genético, em comparação aos métodos bacteriológicos, faz com que a técnica de PCR se torne uma alternativa prática aos laboratórios de diagnóstico, uma vez queeste método elimina o tempo de incubação, isolamento e testes bioquímicos em micro-organismos de crescimento fastidioso, com poucas características bioquímicas para identificação, como é o caso das bactérias do gênero Campylobacter (ON ; HARRINGTON, 2001; Moreno, 2001). A extração de DNA das amostras é obtida das fezes e da cloaca e sua acurácia depende dos métodos de pré-enriquecimento e isolamento direto, indicando que esses dois métodos podem ser utilizados para extração de DNA, pois permitem uma multiplicação considerável do patógeno (KuANA et al., 2008). Um fator muito importante para adoção das metodologias moleculares para Campylobacter sp. é a ausência de metodologia padronizada e seu difícil cultivo (HIETT et al., 2002).

A capacidade de identificação e diferenciação entre as espécies de Campylobacter é importante para se obter a fonte de inóculo e identificar as vias de transmissão (Frost, 2001; WASSENAAR; NEWELL, 2000). Oligonucleotídeos iniciadores (primers) utilizados na PCR são capazes de distinguir entre uma ou mais combinações de espécies já descritas de Campylobacter termotolerantes (Al RASHID et al., 2000; CHUMA et al., 2000; Cloak; Fratamico, 2002).

As técnicas moleculares podem ser realizadas rapidamente e são relativamente baratas mas, infelizmente, muitas dessas que estão disponíveis atualmente para Campylobacter sp. sofrem com a falta de sensibilidade ou especificidade, que pode ser suprida através da combinação de amplificações por PCR e clivagens destes amplicons por enzimas de restrição (HurTADO; OWEN, 1997; FERMER; ENGVALL, 1999; Olive; BeAn, 1999; Gorkiewicz et al., 2003; ON; JORDAN, 2003).

O uso pareado dessas técnicas amplia consideravelmente a possibilidade de caracterizar as cepas genotipicamente, sendo que os critérios de aceitação desses protocolos estão baseados na capacidade de discriminar diferentes clones, na confiabilidade dos resultados no âmbito interlaboratorial, na praticidade, no custo e na possibilidade de identificar isolados e agrupá-los de acordo com sua importância epidemiológica (GOMEs et al., 2006). Os genes utilizados com frequência no diagnóstico molecular das espécies de Campylobacter sp., devido a sua alta especificidade, são HIP, codificador da hipuricase, e flaA, que codifica a flagelina (Gomes et al., 2006).

Microarranjos (microarray) espécie-específicos já foram descritos para uma rápida identificação de Campylobacter spp. (KeRAmAs et al., 2003; VolOKHOV et al., 2003). Este método apresenta grande potencial para estudos epidemiológicos mas, dado ao custo da tecnologia empregada e às dificuldades para a implantação do microarray, na maioria dos laboratórios clínicos, atualmente não têm sido utilizado nas análises de rotina (KLENA et al., 2004).

KLENA et al. (2004), visando suprir as dificuldades encontradas durantes as análises laboratoriais de Campylobacterspp., desenvolverama PCR multiplex, baseada na sequência de diferentes nucleotídeos do gene IpxA, para distinguir entre C. coli, C. jejuni, C. lari e C. upsaliensis, sendo este método rápido, sensível e específico.

\section{Listeria monocytogenes}

\section{Diagnóstico convencional}

$\mathrm{Na}$ microbiologia tradicional, diversos caldos seletivos de enriquecimento e ágares disponíveis para recuperação e multiplicação de L. monocytogenes a partir de espécimes ambientais e de alimentos. Além disso, são necessários vários testes bioquímicos para a classificação taxonômica dos isolados e confirmação do gênero para a identificação da espécie. No mercado está presente uma grande variedade de kits para realizar testes bioquímicos a partir de culturas puras, tornando a identificação simples e rápida (ReVOlLedo; FerReira, 2009).

Uma técnica muito utilizada é a de enriquecimento a frio que é baseada na taxa de recuperação de bactérias em temperaturas de $4^{\circ} \mathrm{C}$, entretanto, apesar de essa técnica ter sido útil, o prolongado tempo de incubação necessário para a obtenção de resultados foi sua principal desvantagem, especialmente em situações de surto, o que veio a estimular a utilização de testes antimicrobianos com meios seletivos. O meio para o enriquecimento deve ser escolhido considerando o tipo da amostra em teste, a qualidade e quantidade do agente possivelmente presente e o tipo de microbiota acompanhante, ou seja, os meios de cultura poderão variar de acordo com a natureza da amostra a ser analisada.

O diagnóstico da listeriose causada pela $L$. monocytogenes inicia pela obtenção de amostras das fezes, medula, sangue e cérebro provenientes das aves ou do meio ambiente. Os meios de culturas utilizados são ALOAgar, BCM L. monocytogenes, CHROMagar, ágar PALCAM, ágar Oxford, ágar sangue, ágar sangue com telurito de potássio 0,05\%. Para identificação dessa bactéria devemos observar: bacilo em célula única ou cadeia curta, Gram positivo ß-hemolítico na coloração, colônia branca, 
lisa em ágar sangue e não há crescimento em meio sólido no ágar MacConkey (NorTON et al., 2000). Os testes bioquímicos são observados: não reduz nitrato, fermentação de açúcar: ramnose positivo, a-metil-D-manosídeo positivo, xilose negativo, ribose negativo, amido solúvel negativo. As amostras podem ser multiplicadas em embriões de galinha de 10 dias de idade inoculadas via saco alantóide (REISSBRODT, 2004).

\section{Diagnóstico molecular}

Asindústrias dealimentos necessitam de metodologias rápidas e sensíveis para monitorar a incidência de L. monocytogenes, principalmente em razão do fato das técnicas convencionais de isolamento e identificação de Listeria necessitarem de etapas trabalhosas e de longa duração, o que muitas vezes pode levar semanas de enriquecimento e de cultivo em meios seletivos, contradizendo a urgência do controle epidemiológico (Revolledo; Ferreira, 2009). Nas últimas décadas, a utilização das técnicas de PCR na detecção e identificação de L. monocytogenes tem se demonstrado eficiente, segundo vários trabalhos (McGinNIS, 2006).

Técnicas de biologia molecular têm sido aplicadas na caracterização de L. monocytogenes, como, por exemplo, PCR, análise por enzimas de restrição (REA), eletroforese em gel decampo pulsado (PFGE), análise randômica do DNA polimórfico (RAPD), tipificação ribossomal, imuno-cromatografia, fluorescência e sequenciamento de bases nucleotídicas ou aminoácidos; é válido ressaltar que a análise dos produtos das reações também é de grande importância para a fidelidade do diagnóstico como, por exemplo, a utilização da eletroforese em gel de agarose e a hibridização em fase sólida (REISSBRODT, 2004).

A utilização da técnica de PCR Multiplex, com mais de um par de primers na mesma reação, possibilita a amplificação simultânea de várias sequências de DNA, o que contribui para a identificação do gênero Listeria e a confirmação de espécies como, por exemplo, a utilização do gene iap, neste tipo de técnica de PCR, para diferenciação das espécies patogênicas (BUBERT, 1999)

BYun et al. (2001) utilizaram a técnica de RAPD para tipificar L. monocytogenes isolada de carnes na Coreia, e puderam concluir que esta técnica auxilia nos trabalhos epidemiológicos de L. monocytogenes, além de outros micro-organismos. A PCR em tempo real (Real-time PCR) obteve bom desempenho para detecção equantificação de L. monocytogenes e Listeria innocua, segundo RodríGUEZ-LÁZARo (2009). Portanto, métodos moleculares de identificação, caracterização e análise da variabilidade vêm sendo muito utilizados na ampliação de conhecimentos sobre as características moleculares dos micro-organismos.

Em estudo realizado com a técnica de PCR da proteína associada com virulência (p60) do gene iap em 48 cepas de Listeria spp. isoladas de diferente tipos de alimentos, Cocolin et al. (2002), utilizando cinco pares de primers específicos, pode diferenciar estas cepas em cinco espécies (L. monocytogenes, $L$. innocua, L. ivanovvi, L. welshimeri e L. seeligeri). LONG et al. (2008) desenvolveram e padronizaram a Q-PCR para detectar e quantificar L. monocytogenes através da detecção do gene $h l y$, responsável pela produção da listeriolisina $\mathrm{O}$. De acordo com estes autores, além da rápida detecção, esse método permitiu a quantificação de L. monocytogenes o que pode ser útil para verificar a presença deste patógeno tanto no diagnóstico clínico como em alimentos.

\section{CONCLUSÃO}

Os micro-organismos estudados são de grande importância quando nos referimos aos transtornos alimentares. Por essa razão, técnicas que apresentem um diagnóstico preciso e eficiente são cada vez mais necessárias para evitar surtos de infecções, que envolvem danos a saúde publica e altos custos. O diagnóstico tradicional, envolvendo os métodos analíticos oficiais para determinação da sanidade de alimentos, principalmente no Brasil, ainda continua sendo realizado por longo período, devido ao fato de ser eficiente. Entretanto, as técnicas moleculares estarão sendo utilizadas com mais frequência com o decorrer dos tempos, a sua utilização vem contribuir com as técnicas tradicionais proporcionando, assim, diagnósticos cada vez mais precisos e em curto prazo de tempo. Assim, podemos ressaltar que o diagnóstico molecular é um campo em franco avanço científico e tecnológico, no qual novas técnicas moleculares estão em desenvolvimento para o diagnóstico de bactérias em alimentos.

\section{AGRADECIMENTO}

À FINEP (Financiadora de Estudos e Projetos) e ao Programa subvenção/Pesquisador na Empresa, pelo apoio financeiro ao projeto $n^{\circ}$ 01/08/031900.

\section{REFERÊNCIAS}

AL RASHID, S.T.; DAKUNA, I.; LOUIE, H.; NG, D.; VANDAMME, P.; JOHNSON, W.; CHAN, V.L. Identification of Campylobacter jejuni, C. coli, C. lari, C. upsaliensis, Arcobacter butzleri, and A. butzleri-like species based on the glyA gene. Journal of Clinical Microbiology, v.38, p.1488-1494, 2000.

AL-SOUD, W.A.; RADSTRÖM, P. Capacity of nine 
thermostable DNA polymerases to mediate DNA amplification in the presence of PCR-inhibiting samples. Applied and Environmental Microbiology, v.64, n.10, p.3748-3753, 1998.

ALVAREZ, J.; SOTA, M.; VIVANCO, A.B.; PERALES, I.; CISTERNA, R.; REMENTERIA, A.; GARAIZAR, J. Development of a multiplex PCR technique for detection and epidemiological typing of salmonella in human clinical samples. Journal of Clinical Microbiology, v.42, n.4, p.1734-1738, 2004.

AMERICAN PUBLIC HEALTH ASSOCIATION. Compendium of methods for the microbiological examination of foods. 4.ed.Washington, DC: APHA, 2001.

BARNES, H.J.; CALNEK, B.W.; BEARD, C.H.; McDOGALD, L.R.; SAIF, Y.M. Diseases of poultry. 10.ed.Ames, Iowa: Iowa State University Press, 1997. p.235-245.

BARON, E.J.; PETERSON, L.R.; FINEGOLD, S.M. Diagnostic microbiology. 9.ed. St. Louis: Mosby, 1994. 958p.

BARROS, V.R.M. Salmonella spp: sua transmissão através dos alimentos. Higiene Alimentar, v.16, n.94, p.15-19, 2002.

BAUMLER, A.J.; HEFFRON, F.; REISSBRODT, R. Rapid detection of Salmonella enterica with primers specific for iroB. Journal of Clinical Microbiology, v.35, p.12241230, 1997.

BENNET, A.R.; GREENWOOD, D.; TENNANT, C.; BANKS, J.G.; BETTS, R.P. Rapid and definitive detection of Salmonella in foods by PCR. Letters in Applied Microbiology, v.26, p.437-441, 1998.

BEUMER, R.R.; BRINKMAN, E.; ROMBOUTS, F.M. Enzyme-linked immunoassays for the detection of Salmonella spp.: a comparison with other methods. International Journal of Food Microbiology, v.12, p.363-374, 1991.

BLACKBURN, C.W. Rapid and alternative methods for the detection of salmonellas in foods. A review. Journal of Applied Bacteriology, v.75, p.199-214, 1993.

BOHRER, . L.; FILARDI, . S.; SIMON, F.; IKUNO, A. A.; MUELLER, .. K. Presença de anticorpos contra o vírus da rinotraqueíte infecciosa dos bovinos/vulvovaginite pustular infecciosa (IBR/IPV) em capivaras (Hydrochoeris hydrochoeris, LIN.). Arquivos do Instituto Biológico, São Paulo, v.54, n.1/4, p.45-48, 1987.

BRASIL. Ministério da Agricultura, do Abastecimento e da Reforma Agrária. Secretaria de Defesa Agropecuária. Portaria $\mathrm{n}^{\circ} 8$ de 23 de janeiro de 1995. Aprova alterações introduzidas no método analítico de carcaça de aves e pesquisa de Salmonella. Diário Oficial da União, 27 jan. 1995. Seção I, p.1182.

BUBERT, A. Detection an differentiation of Listeria spp. by a single reaction based in Multiplex PCR. Applied and Environmental Microbiology, v.65, n.10, p.4688-4692, 1999.

BUTZLER, J.P. Campylobacter, from obscurity to celebrity. Clinical Microbioologd and Infection, v.10, p.86- 876, 2004.

BYUN, S.K.; JUNG, S.C.; YOO, H.S. Random amplification of polymorphic DNA typing of Listeria monocytogenes isolated from meat. International Journal of Food Microbiology, v.69, p.227-235, 2001.

CARVALHO, A.C.F.B.; LIMA, V.H.C.; PEREIRA, G.T. Determinação dos principais pontos de risco de contaminação de frangos por Campylobacter, durante o abate industrial. Higiene Alimentar, v.16, p.89-94, 2002.

CHRISTOPHER, F.M.; SMITH, C.G.; VANDERZAN, T.C. Examination of poultry giblets, raw milk and meat for Campylobacter fetus subsp. jejuni. Journal of Food Protection, v.45, p.260- 262, 1982.

CHUMA, T.; HASHIMOTO, S.; OKAMOTO, K. Detection of thermophilic Campylobacter from sparrows by multiplex PCR: the role of sparrows as a source of contamination of broilers with Campylobacter. The Journal of Veterinary Medical Science, v.62, p.121-1295, 2000.

CLOAK, O.M.; FRATAMICO, P.M. A multiplex polymerase chain reaction for the differentiation of Campylobacter jejuni and Campylobacter coli from a swine processing facility and characterization of isolates by pulsed-field gel electrophoresis and antibiotic resistance profiles. Journal of Food Protection, v.65, p.266-273, 2002.

COCOLIN, L.; RANTSIOU, K.; IACUMIN, L.; CANTONI, C.; COMI, G. Direct Identification in Food Samples of Listeria spp. and Listeria monocytogenes by Molecular Methods. Applied and Enviromental Microbioloy, v.68, n.12, p.6273-6282, 2002.

COHEN, N.D.; NEIBERGS, H.L.; McGRUDER, E.D.; WHITFORD, H.W.; BEHLE, R.W.; RAY, P.M.; HARGIS, B.M. Genus-specific detection of Salmonellae using the polymerase chain reaction (PCR). Journal of Veterinary Diagnostic Investigation, v.5, p.368-371, 1993.

CORRÊA, W.M.; CORREAA, C.N.M. Enfermidades infecciosas dos mamíferos domésticos. 2.ed. Rio de Janeiro: Medsi, 1992. 843p.

DEDIOL, C.; NACIF, N.J.; ANDRÉ, S.; SÁNCHES, M.L.; ACOSTA, M.V.; SFREDDO, S.E. Incidência de Listeria monocytogenes en carne vacuna fresca en el Área del Gran Mendoza. Higiene Alimentar, v.16, n.102/103, p.1316, 2002.

DOUBLET, B.; DOUARD, G.; TARGANT, H.; MEUNIER, D.; MADEC, J.Y.; CLOECKAERT, A. Antibiotic marker modifications of lambda Red and FLP helper plasmids, pKD46 and pCP20, for inactivation of 
chromosomal genes using PCR products in multidrugresistant strains. Journal of Microbiological Methods, v.75, n.2, p.359-361, 2008.

FERME’R, C.; ENGVALL, E.O. Specific PCR identification and differentiation of the thermophilic campylobacters Campylobacter jejuni, C. coli, C. lari, and C. upsaliensis. Journal of Clinical Microbiology, v.37, p.330-3373, 1999.

FLOWERS, R.S.; KLATT, M.J.; KEELAN, S.L. Visual immunoassay for detection of Salmonella in foods: collaborative study. Journal of the Association of Official Analytical Chemists, v.71, n.5, p.973-980, 1988.

FORTUNA, J.L.; FRANCO, R. Epidemiologic studies of the Salmonella, as casual of infections food. Higiene Alimentar, v.19, n.128, p.33-44, 2005.

FROST, J. A. Current epidemiological issues in human campylobacteriosis. Journal of Applied Microbiology, v.90, p.8S-95S, 2001.

GÁLAN, J.E.; GINNOCHIO, C.; COSTEAS, P. Molecular and functional characterization of the Salmonella invasion gene invA: homology of invA to members of a new protein family. Journal of Bacteriolog, v.174, n.13, p.43384339, 1992.

GANDRA, E.A.; GANDRA, T.K.V.; MELLO, W.S.; GODOI, H.S. Técnicas moleculares aplicadas à microbiologia de alimentos. Acta Scientiarum Technology, v. 30, p.109118, 2008.

GOMES, F.R.; CURCIO, B, .; LADEIRA, S.R.L.; FERNÁNDEZ, H.; MEIRELES, M.C.A. Campylobacter jejuni occurrence in chicken fecal samples from small Properties in Pelotas, southern of Brazil. Brazilian Journal of Microbiology, v.37, p.375-378, 2006.

GORKIEWICZ, G.; FEIERL, G.; SCHOBER, C.; DIEBER, F.; KO־FER, J.; ZECHNER, R.; ZECHNER, E.L. Speciesspecific identification of campylobacters by partial $16 \mathrm{~S}$ rRNA gene sequencing. Journal of Clinical Microbiolology, v. 41, p.257-2546, 2003.

HIETT, K.L.; COX, N.A.; STERN, N. Direct Polymerase Chain Reaction Detection of Campylobacter spp. In Poultry Hatchery Samples. Avian Diseases, v.46, n.1, p.219-223, 2002.

HOCHBERG, A.M.; ROERING, A.; GANGAR, V.; CURIALE, M.; BARBOUR, W.M. ROZINSI., P.M. Sensitivity and specificity of the BAX® for screening Listeria monocytogenes assay. Internal validation and independent laboratory study. Journal of AOAC Internation, v.84, n.4, p.108-1097, 2001.

HOORFAR, J.; BAGGESEN, D.L.; PORTING, P.H. A PCR-based strategy for simple and rapid identification of rough presumptive Salmonella isolates. Journal of Microbiological Methods, v.35, p.7-84, 1999.

HUDSON, R.C.; QUIST, C.; LEE, M.D.; KEYES, K.;
DODSON, S.V.; MORALES, C.; SANCHEZ, S.; WHITE, D.G.; MAURER, J.J. Genetic relatedness of Salmonella isolates from nondomestic birds in Southeastern United States. Journal of Clinical Microbiology, v.38, n.5, p.18601865, 2000.

HUNT, J.M.; ABEYTA, C.; TRANT, T. Campylobacter In: Bacteriological manual online. 8.ed. Revision A. Washington, DC: Center for Food Safety and Applied Nutrition, FDA, 2001. cap. 7.

HURTADO, A.; OWEN, R.J. A molecular scheme based on $23 \mathrm{~S}$ rRNA gene polymorphisms for rapid identification of Campylobacter and Arcobacter species. Journal of Clinical Microbiology, v.35, p.241-2404, 1997.

JEYASEKARAN, G.; KARUNASAGAR, I.; KARUNASAGAR, I. Incidence of Listeria spp. in tropical fish. International Journal of Food Microbiology, v.31, p.333-340, 1996.

KERAMAS, G.; BANG, D.D.; LUND, M.; MADSEN, M.; RASMUSSEN, S.E.; BUNKENBORG, H.; TELLEMAN, P.; CHRISTENSEN, C.B.V. Development of a sensitive DNA microarray suitable for rapid detection of Campylobacter spp. Mollecular Cell Probes, v.17, p.187-196, 2003.

KLENA, J.D.; PARKER, C.T.; KNIBB, K.; IBBITT, J.C.; DEVANE, P.M.; HORN, S.T.; MILLER, W.G.; KONKEL, M.E. Differentiation of Campylobacter coli, Campylobacter jejuni, Campylobacter lari, and Campylobacter upsaliensis by a multiplex PCR developed from the nucleotide sequence of the lipid A gene lpxA. Journal $f$ Clinical Microbiology, v.42, p.559-5557, 2004.

KONEMAN, E.W.; ALLEN, S.D.; JANDA, W.M.; SCHRECKENBERGER, P.C.; WINN JUNIr., W.C. Diagnóstico microbiológico: texto e atlas colorido. 5.ed. Rio de Janeiro: MEDSI, 2001. 1465p.

KUANA, S.L.; SANTOS, L.R.; RODRIGUES, L.B.; BORSOI, A.; KELLERMANN, A.; SALLE, C.T.P.; MORAES, H.L.S.; NASCIMENTO, V.P. Pré-enriquecimento e isolamento direto para identificaçãode Campylobacter em swabs cloacais e carcaças de frango. Acta Scientiae Veterinariae, v.36, n.1, p.21-24, 2008.

KUMAR, S.; BALAKRISHNA, K.; BATRA, H.V. Detection of Salmonella enterica serovar Typhi (S. Typhi) by selective amplification of invA, viaB, fliC-d and prt genes by polymerase chain reaction in mutiplex format. Letters in Applied Microbiology, v.42, n.2, p.149-154, 2006.

LIESACK, W.; STACKEBRANDT, E. Occurrence of novel groups of the domain bacteria as revealed by analysis of genetic material isolated from na australian terrestrial environment. Journal of Bacteriology, v.174, n.15, p.5072-5078, 1992.

LONG, F.; ZHU, X.; ZHANG, Z.; SHI, X. Development of a Quantitativen Polymerase Chain Reaction Method Using a Live Bacterium as Internal Control for the Detection of Listeria monocytogenes. Diagnostic Microbiology 
and Infectious Disease, v.12, p.1-8, 2008.

McGINNIS, L. New Methods for Detecting Listeria. In: U.S. Department of Agriculture. Disponível em: <http:/ / www.ars.usda.gov/is/pr/2006/061012.htm>. Acesso em: 16 jul. 2010.

MORENO, Y.; HERNÁNDEZ, M.; FÉRRUS, M.A.; ALONSO, J.L.; BOTELLA, S. Direct detection of thermotolerant Campylobacters in chicken products by PCR and in situ hybridization. Revista de Microbiologia, v.152, p.577-582, 2001 .

NORTON, D.M.; McCAMEY, M.; BOOR K.J.; WIEDMANN, M. Application of the BAX® for screening/genus Listeria polymerase chain reaction system for monitoring Listeria species in coldsmoked fish and in the smoked fish processing environment. Journal of Food Protection, v.63, n.3, p.343-346, 2000.

OLIVE, D.M.; BEAN, P. Principles and applications of methods for DNA-based typing of microbial organisms. Journal of Clinical Microbiology, v.37, p.1661-1669, 1999.

OLIVEIRA, S.D.; SANTOS, L.R.; SCHUCH, D.M.T.; SILVA, A.B.; SALLE, C.T.P.; CANAL, C.W. Detection and identification of salmonellas from poultry-related samples by PCR. Veterinary Microbiology, v.87, p.25-35, 2002.

ON, S.L.W.; HARRINGTON, C.S. Evaluation of numerical analysis of PFGE DNA profiles for differentiating Campylobacter fetus subspecies by comparison with phenotypic, PCR and 16S rDNA sequencing methods. Journal of Applied Microbiology, v.90, p.285-293. 2001.

ON, S.L.W.; JORDAN, P.J. Evaluation of 11 PCR assays for species-level identification of Campylobacter jejuni and Campylobacter coli. Journal of Clinical Microbiology, v.41, p.330-336, 2003.

RAHN, K.; DE GRANDIS, S.A.; CLARKE, R.C.; McEWE, S.A.; GALÁN, J.E.; GINOCCHIO, C.; CURTIS, R.; GYLES, C.L. Amplification of invA gene sequence of Salmonella typhimuriun by polymerase chain reaction as a specific method of detection of Salmonella. Molecular and Cellular Probes, v.6, p.271-279, 1992.

RALL, V.L.M.; RALL, R.; ARAGON, L.C.; SILVA, M.G. Evaluation of three enrichment broths and five plating media for Salmonella detection in poultry. Brazilian Journal of Microbiology, v.36, n.2, p.147-150, 2005.

REISSBRODT, R. New chromogenic plating media for detection and enumeration of pathogenic Listeria spp. - an overview. International Journal of Food Microbiology, v.95, p.1-9, 2004.

REVOLLEDO, L.; FERREIRA A.J.P. Patologia aviária. Manole: Barueri, 2009. p.34-66.

RODRÍGUEZ-LÁZARO, D. Quantitative detection of
Listeria monocytogenes and Listeria innocua by real-time PCR: assessment of hly, iap, and lin02482 targets and amplifluor technology. Applied and Environmental Microbiology, v.70, n.3, p.1366-1377, 2009.

ROONEY, R.M.; CRAMER, E.H.; MANTHA, S.; NICHOLS, G.; BARTRAM, J.K.; FARBER, J.M.;

BENEMBAREK, P.K. A review of outbreaks of foodborne disease associated with passenger ships: evidence for risk management. Public Health Reports, v.119, n.4, p.427-434, 2004.

SAMBROOK, J.; RUSSELL, D.W. The condensed protocols from molecular cloning: a laboratory manual. New York: Cold Spring Harbor Laboratory Press, 2006.

SANTOS, L.R.; NASCIMENTO, V.P.; OLIVEIRA, S.D.; FLORES, M.L.; PONTES, A.P.; PILOTTO, F.; NEVES, N.; SALLE, C.T.P.; LOPES, R.F.F. Identificação de Salmonella através da reação em cadeia pela polimerase (PCR). Arquivos da Faculdade de Veterinária da UFRGS, v.29, p.87-92, 2001.

SANTOS, L.R.; NASCIMENTO, V.P.; OLIVEIRA, S.D.; PONTES, A.P.; FLORES, M.L.; FORELL, F.; PILOTTO, F.; NEVES, N.; SALLE, C.T.P.; LOPES, R.F.F. Protocolos para extração de DNA de Salmonella. Arquivos da Faculdade de Veterinária da UFRGS, v.27, n.2, p.93-101, 1999.

SCARCELLI, E.; MIYASHIRO, S.; PIATTI, R.M.; CAMPOS, F.R.; CASTRO, A.G.M.; CARDOSO, M.V.; FRANCISCO, W.; RICHTZENHAIN, L.J.; GENOVEZ, M.E. Emprego da técnica do polimorfismo de comprimento dos fragmentos de restrição (RFLP) do produto obtido pela reação da polimerase em cadeia (PCR) do gene FLA na subtipagem de amostras de Campylobacter jejuni subesp. jejuni isoladas de frangos de corte e humanos. Arquivos do Instituto Biológico, São Paulo, v.70, n.1, p.1-5, 2003.

SCHRANK, I.S. Aplicação de método baseado em PCR para a detecção de Salmonella em produtos da indústria avícola e em amostras clínicas. Revista Brasileira de Ciência Avícola, p.105S, 2000.

STONE, G.G.; OBERST, R.D.; HAYS, M.P, McVEY, S.; CHENGAPPA, M.M. Detection of Salmonella serovars from clinical samples by enrichment broth cultivation-PCR procedure. Journal of Clinical Microbiology, v.32, n.7, p.1742-1749, 1994a.

STONE, G.G.; OBERST, R.D.; HAYS, M.P.; McVEY, S.; GALLAND, J.; CURTSS, R.; KELLY, S.M.; CHEMGAPPA, M. Detection of Styphimurium from rectal swabs of experimentally infected beagles by short cultivation and PCR hybridization. Journal of Clinical Microbiology, v.33, n.5, p.1292-1295, 1994b.

TUCHILLI, L.M.; KODAMA, H.; IZUMOTO, Y.; MUKAMOTO, M.; FUCATA, T.; BABA, T. Detection of Salmonella Gallinarum and $S$. Typhimurium DNA in experimentally infected chicks by polimerase chain reaction. Journal of Veterinary Medical Science, v.1, n.57, p.59-63, 1995. 
VOLOKHOV, D.; CHIZHIKOV, V.; CHUMAKOV, K.; RASOOLY, A. Microarray-based identification of thermophilic Campylobacter jejuni, C. coli, C. lari, and C. upsaliensis. Journal of Clinical Microbiology, v.41, p.4071-4080, 2003.

WARD, D.M.; WELLER, R.; BATESON, M.M. $16 S$ rRna sequences reveal numerous uncultured microorganisms in a natural community. Nature, v.345, p.63-67, 1990.

WASSENAAR, T.M.; NEWELL, D.G. Genotyping of Campylobacter spp. Applied and Environmental Microbiology, v.66, p.1-9, 2000.
YAN, S.; PENDRAK, M.; FOLEY, S.; POWERS, J. Campylobacter infection and Guillain-Barré syndrome: public health concerns from a microbial food safety perspective. Clinical and Applied Immunology Reviews, v.5, p.285-305, 2005.

Recebido em 17/6/09

Aceito em 21/7/10 